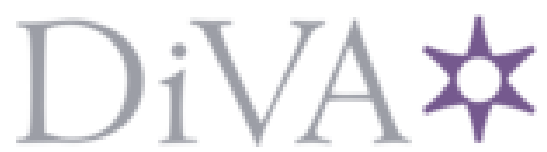

http://www.diva-portal.org

This is the published version of a paper presented at 14th International Technology, Education and Development Conference, Valencia, March 2-4, $2020 .$.

Citation for the original published paper:

Dvorak, M. (2020)

Native Multilingualism and Stroop Effect: a Pilot Study Examining the Relationships Between the Two Variables

In: L. Gómez Chova, A. López Martínez, I. Candel Torres (ed.), INTED2O2O

Proceedings (pp. 8533-8541). Valencia: The International Academy of Technology, Education and Development

https://doi.org/10.21125/inted.2020.2326

N.B. When citing this work, cite the original published paper.

Permanent link to this version:

http://urn.kb.se/resolve?urn=urn:nbn:se:sh:diva-40357 


\title{
NATIVE MULTILINGUALISM AND STROOP EFFECT - A PILOT STUDY EXAMINING THE RELATIONSHIPS BETWEEN THE TWO VARIABLES
}

\author{
M. Dvorak \\ Södertörns University, Stockholm (SWEDEN)
}

\begin{abstract}
Multiple studies point out a positive relationship between bilingualism (multilingualism), cognitive development of children and their academic performance at the early age. The Stroop Test is often used as one of the methods of assessing subjects' executive function of inhibition (the ability to suppress dominant responses), which appears to be enhanced in bilingual/multilingual individuals compared to their monolingual counterparts. The better executive control in bilinguals/multilinguals, which the function of inhibition represents only a part of (besides shifting, i.e. the ability to switch over between tasks, and monitoring, i.e. the ability to update information in the working memory), is believed to stem from these individuals switching over between their languages as well as their need to suppress the other language-related information irrelevant in the given language context.
\end{abstract}

This paper describes a pilot experiment preceding a study of a larger scale whose main objective is to obtain data to be used to assess a possible relationship between the number of mother tongues Swedish university students have a command of and their performance at the Stroop Test.

Keywords: Native multilingualism, Stroop Test, executive control, academic performance, pilot study.

\section{INTRODUCTION}

Despite some studies which warned of disastrous effects of bilingualism on cognitive development of children (for information on research in the early 1900s see Grosjean (1982)), a number of others provide evidence that bilingualism enhances executive control - a term encompassing cognitive skills such as switching attention between tasks or inhibition of the attention when it comes to the stimuli that need to be ignored (Bialystok and Martin, 2004; Bialystok et al., 2008; Yow and Li, 2005, etc.). Some other authors (Antón et al., 2016; Miake \& Friedman, 2012, etc.) work with the concept of executive functions such as inhibition (the ability to suppress dominant responses), shifting (the ability to switch over between tasks) and monitoring (the ability to update information in the working memory). The enhanced executive control in bilinguals is believed to stem from their continuous exposure to the necessity to switch between their languages as well as their need to suppress the other language-related information which is irrelevant in the given language context. In this respect, the bilinguals are often described as individuals capable of greater interference suppression, or having an improved inhibitory control, compared to their monolingual counterparts (Dagenbach \& Carr, 1994; Dempster, 1992; Diamond \& Taylor, 1996; Bialystok \& Martin, 2004).

To measure the degree of executive and inhibition control, several kinds of tests are used. These range from the Simon task measuring subjects' reaction times in the situations where there is a match between a stimulus and response when it comes to a location, to the Eriksen flanker task where the relevant stimulus is "flanked" by the irrelevant ones, card-sort tasks, where subjects are asked to sort cards according to one set of rules and subsequently another, and the color-based Stroop test, which includes reactions to language-related stimuli. In the Simon task, the speed of a spatial response (e.g. pressing a left or right button) to a spatial stimulus (e.g. the side of the ear a sound is played into) (Simon, 1969) or a non-spatial one (e.g. its shape, color, a pitch of the tone played) (Hübner \& Mishra, 2013; Proctor, 2011) is measured. The Eriksen flanker task, as originally described by Eriksen \& Eriksen (1974), tested subjects' reactions to the stimuli presented in the form of letters flanked by the "noise letters" and measured their reaction times in the situations where the target letters and the noise ones were either congruent (the noise letters identical with the target one) or incongruent (the noise letters different from the target ones). Since then other variants of the task have been used including the ones developed especially for children with the pictures of fish (swimming either left or right) (Yang \& Lust, n.d.). In the card-sort test, subjects can, for instance, be asked to sort cards according to the colors the shapes drawn on the cards are filled with and subsequently sort these according to the shapes per se (Bialystok, 1999; Bialystok \& Martin, 2004). 
When devising the Stroop test, its founder, Ridley Stroop, drew on the law of associative inhibition which Kline describes as "If $a$ is already connected with $b$, then it is difficult to connect it with $k, b$ gets in the way." (Kline, 1921 in Stroop, 1935). In the experiment, Stroop presented pairs of conflicting stimuli (words written in colors (Stimulus 1) different from those that the words denoted (Stimulus 2)) simultaneously and measured how long it took the subjects to name the "right" colors, i.e. the colors in which the words were printed instead of those expressed by the words. The experiment revealed a discrepancy in the subjects' reaction times, similarly to the other tests mentioned above which targeted subjects' reactions to congruent vs incongruent conditions. That is, it took the subjects a longer time to name the colors of the words when these did not correspond to the colors expressed by the words than it took them to name the colors when these were presented in the form of colored squares $-\mathrm{a}$ fact that showed the extent to which a language can interfere with the color-naming process.

Since then, a number of studies (Bialystok et al. 2008; Wang et al. 2016; Heidlmayr et al. 2014 and more) showing that bilinguals tend to exhibit a lower Stroop effect have been conducted. The Stroop effect value is calculated as the difference between the naming reaction time in the situation where the color and the word it is printed in are incongruent and the naming reaction time in the situation where these two are congruent. In this respect, the lower Stroop effect implies a higher degree of semantic contents inhibition - a feature identified in the individuals using more than one language. As the studies point out, the increased inhibitory potential manifested by bilinguals in the Stroop test seems to relate to the language-switching experience these individuals have.

Some studies stress the relationship between the Stroop effect value in bilinguals and other factors such as language proficiency and type of bilingualism (balanced vs unbalanced), age of the bilinguals, duration of immersion in the second language environment, or even some hidden demographic factors that tend to be differently distributed among the bilingual and monolingual groups. When it comes to the language proficiency and the type of bilingualism, Yow \& Li (2015) found out that an earlier age of the second language acquisition and a more balanced use of the two languages result in a smaller interference effect in the Stroop task. Rosselli et al. (2002), who studied Stroop test performance among Spanish-dominant and English-dominant bilinguals, observed that the former were significantly slower in all the test conditions in English and the latter significantly slower in all the test conditions in Spanish. As regards age, Bialystok et al. 2008 reported a greater bilingual advantage in the Stroop task in the older adults. Ivnik et al. (1996) showed there is a significant decline in the Stroop Test performance with advancing age and Cornalli et al. (1962) demonstrated that older adults and children indicate longer response latencies than young adults. The duration of immersion in a second language environment has been documented as a factor influencing the Stroop effect in the subjects' first language (L1) by Heidlmayr et al. (2014), who point out a positive correlation between the two variables while reporting a negative correlation between this effect and the frequency of L2 and L3 use as well as the L2 proficiency. Paap, Johnson \& Savi (2015) point out that the executive functions are affected by the variables of immigrant status, educational level, socio-economic status as well as other factors.

There is also a growing body of research indicating that the language the Stroop task is conducted in affects the Stroop effect values, together with the subjects' proficiency in this language. Thus, for instance, Badzakova-Trajkov et al. (2004) comparing the effect between Macedonian-English bilingual subjects and English monolingual subjects arrived at the conclusion that the bilinguals, who performed the test in both Macedonian and English, had displayed longer reaction times than the monolinguals. This also applies to the times related to congruent and control conditions in their first language, which, as the researchers believe, is indicative of a change in the first language processing due to the acquisition of a second language. In another study, Roselli et al. (2002) tested Spanish-English bilinguals, English monolinguals and Spanish monolinguals using the Stroop test to find out whether there were any differences between the groups. They found out that unbalanced Spanish-dominant bilinguals were significantly slower than the unbalanced English-dominant ones and the balanced bilinguals in the English color-naming condition. Similarly, Yow and Li (2015), who conducted the Stroop test among English-Mandarin young adult bilinguals, show that the more balanced use of two languages and the earlier age of L2 acquisition the smaller the interference effect in the Stroop task.

However, when it comes to between-language interference in the Stroop test conducted the way that requires the subjects to give responses in the language other than the one the stimuli were presented in, the high proficiency in the language that the stimuli are presented in appears to have an opposite effect, i.e. results in greater interference and thus higher values of Stroop effect. This was observed by Sumiya \& Healy (2008), who conducted an experiment with native English speakers showing that the 
between-language interference in these for English stimuli and Japanese responses was greater than for Japanese stimuli and English responses. Moreover, the researchers stress the fact that the Stroop effect is also partly determined by the phonological similarity between the color words in the two languages since this similarity leads to greater interference.

\subsection{Goals of the Study}

The goal of this pilot study was to test the feasibility of a study of a larger scale whose purpose is to find out whether there are any differences in Stroop effect between Swedish native monolingual and native (bi-) multilingual university students in the language which is not their mother tongue and which the students learnt during the course of their previous studies at primary and secondary schools, i.e English. Based on the findings of the studies investigating the relationship between (bi-) multilingualism and inhibition of dominant responses the original hypothesis was that the native (bi-) multilingual students would indicate greater inhibition control and thus lower Stroop effect in English than the native monolingual ones. The aim was to test the initial hypothesis and find out whether the number of mother tongues one acquires as a child in a natural acquisition setting affects the inhibition control within the language one learns in an instruction-based setting, i.e. during their language lessons.

Another aim of the study was to find out whether one can observe a relationship between the perceived proficiency in the subjects' mother tongues and the Stroop effect since the higher proficiency in these was expected to correlate with the Stroop effect values, i.e. the higher the proficiency, the lower the Stroop effect.

\section{METHODOLOGY}

\subsection{Participants}

The Stroop test was conducted on the total of 65 Swedish university students involved in the pilot study, but 6 of them were excluded from it as outliers. These six subjects were both the students with a negative Stroop effect value (perhaps due to their highly fluctuating levels of attention during the test) and those whose number of color identification errors exceeded 10, i.e. risk-takers prioritizing speed over accuracy in the color identification process. Out of the remaining 59 participants, 26 were native monolinguals (having one native language) and 33 had more than one native language (26 native bilinguals and 7 native trilinguals). The average age was 26.24 years (SD $=6.71$ ), the youngest participant was 19- and oldest 53-years-old. There were 44 females and 15 males in the group.

At the time of the study (February 2018 - May 2019), 10 students were enrolled in the Elementary School K-3 teacher training program, 22 in the Elementary School 4-6 teacher training program, 16 in the Secondary School teacher training program and 11 of them in the English Studies program. All of the native monolingual students acquired Swedish as their mother tongue and all of the native bilingual and multilingual students learnt Swedish before reaching their adolescence mostly through interaction with their teachers and peers as early as their preschools and during their out-of-school activities involving their Swedish-speaking schoolmates and friends. In this respect, Swedish was considered their second (and in some of them third) native language. It was also the language in which all of them studied most subjects within their programs. The languages the bilinguals and trilinguals indicated as their first or second native ones, i.e. those they had spoken with their parent(s) since their birth, were: Arabic, Changana, Finnish, Norwegian, Greek, Kurdish, Malaysian, Ronga, Russian, Serbian, Somali, Spanish, Syrian, Thai, Tigrinya, Turkish, Urdu, and Yugoslavian. All of the participants studied English in the past, i.e. at their primary and secondary schools, and their knowledge of the language ranged from B2 to C1 CEFR levels, which also enabled them to study English-related courses in it such as methodology of teaching English, literary studies, and university grammar of English.

\subsection{Data Collection Methods}

The data pertinent to the participants' mother tongues such as their number, their perceived oral and written proficiency in these and the information about whether the students still used their mother tongues at home as well as to what extent were collected through questionnaires distributed among the students at the beginning of the study. The questions targeting the mother tongues required the participants to specify which of them they had spoken at home as children and with whom. The 
students were asked to mark the degree of their perceived oral and written proficiency in these on the Likert scale of 1-5 with 1 representing "extremely bad" and 5 "extremely good". They were also asked to describe to what extent and how often, if any, they still used the mother tongues with their parents, relatives or friends.

To measure the participants' inhibitory control, a computerized version of the Stroop test available at https://www.psytoolkit.org/ was used. The task consisted of two conditions on which the participants were tested: a) congruent trials, where the words denoting the same colors as the ones they were displayed in on the screen were used, b) incongruent trails, where the colors denoted by the words did not match those the words were displayed in. For each trial type the students were instructed to identify the color of the word as quickly as possible by pressing a corresponding key on their keyboards. The keys the subjects were instructed to press were those that had on themselves the initial letters of names of the colors the words were printed in. Therefore, when the word "red", for instance, got displayed in blue color, the students were supposed to press the $b$ key ("b" standing for "blue"). In this respect, the students were explicitly asked to ignore the meaning of the words and focus on the colors in which the words were displayed instead.

There were four colors used in the test (red, yellow, blue and green) and the students were instructed to press the $r, y, b$ and $g$ keys to indicate these. Before each of the words was presented in the middle of the screen against the black background until the participant responded but no longer than 2 seconds, a fixation cross was displayed in the same position for 200 milliseconds for the participant to know where the word would appear. Once the participant made their choice, either a word "correct" or "wrong" was displayed to them for 500 milliseconds depending on whether their choice was correct or incorrect. The script in which the test was run measured the participants' reaction times in both the congruent and incongruent conditions and counted the errors they made by indicating a wrong color. The Stroop test was run under these conditions twice - once as a practice session with thirty trials, whose purpose was to make sure all the participants understood what they were supposed to do as well as to enable them to practice the key-color associations, and then as the test itself with sixty test trials. Half of test trials were in the congruent condition and the other half in the incongruent one. They were mixed and presented to the subjects randomly.

The original hypotheses were that those with more than one native language would manifest a better inhibitory control indicated by a lower value of the Stroop effect than the native monolinguals would and that the higher proficiency in the native languages among native (bi-) multilinguals would have a positive effect on their users' capacity to inhibit irrelevant stimuli.

\subsection{Data Analysis Methods}

The main Stroop effect value for those who were included in the experiment $(\mathrm{N}=59)$ was calculated for the individual participants according to the following formula using the reaction times recorded for congruent as well as incongruent trials and collected together with the information about the erroneous choices from files saved on a server once the tests had been completed:

Stroop Effect $=$ Incongruent Trials Total Time - Congruent Trials Total Time

The Stroop effect values were subsequently compared for native monolinguals and bilinguals (+ trilinguals) and statistically analyzed using the Independent-Samples $T$ test to find out whether there were any statistically significant differences in the Stroop effect between those who have been exposed to one mother tongue and the ones exposed to two or more.

The information obtained from the questionnaires about the perceived proficiency in the native bilingual and multilingual students' mother tongues was used to analyze any possible relationship between this variable and the inhibitory control indicated by Stroop test results with the aid of Pearson bi-variate analysis.

\section{RESULTS}

The Stroop effect means are presented in Table 1. As one can see, the mean Stroop effect for the native monolinguals is $123.35 \mathrm{~ms}$ while for native bilinguals (multilinguals) it is $143.79 \mathrm{~ms}$. One can therefore conclude that native monolinguals, on average, indicate a little shorter Stroop effect time (about $20 \mathrm{~ms}$ ) than the native bilinguals (multilinguals). In this respect, contrary to the initial hypothesis and previous research, the Stroop effect in the native bilinguals/multilinguals is slightly greater than in the monolingual group. 
The table also shows that the native monolinguals involved in the experiment have shorter average reaction times in both the conditions than their bilingual/multilingual counterparts, i.e. in the congruent trials they appear to react about $41 \mathrm{~ms}$ and in the incongruent trials about $61 \mathrm{~ms}$ faster than the latter.

Table 1: Stroop Effect in Native Monolinguals and Native Bilinguals (Multilinguals).

\begin{tabular}{|l|c|c|c|c|c|}
\hline $\begin{array}{c}\text { Native Monolingual / } \\
\text { Native Bilingual } \\
\text { (Multilingual) }\end{array}$ & Number & $\begin{array}{c}\text { Participants' Reaction } \\
\text { Time for Congruent } \\
\text { Trials (Mean) in ms }\end{array}$ & $\begin{array}{c}\text { Participants' Reaction } \\
\text { Time for Incongruent } \\
\text { Trials (Mean) in ms }\end{array}$ & $\begin{array}{c}\text { Mean } \\
\text { Stroop } \\
\text { Effect in ms }\end{array}$ & SD \\
\hline Native Monolinguals & 26 & 741.04 & 864.46 & 123.35 & 59.349 \\
\hline $\begin{array}{l}\text { Native Bilinguals / } \\
\text { Multilinguals }\end{array}$ & 33 & 781.58 & 925.27 & 143.79 & 82.033 \\
\hline Mean Difference & & 40.537 & 60.811 & 20.442 & \\
\hline
\end{tabular}

However, the independent samples T-test run on the acquired data shows that for the test group of this size there is no statistically significant difference in Stroop effect for native monolinguals $(M=$ 123.31, $S D=59.35)$ and native bilinguals/multilinguals $(M=143.79, S D=82.033)$ conditions; $t(57)=$ 1.07, $p=0.29$. As regards the reaction time for congruent trials, the test shows that the difference in these for native monolinguals $(M=741.04, S D=188.90)$ and native bilinguals/multilinguals $(M=$ $781.58, S D=169.80)$ conditions; $t(57)=-0.87, p=0.39$, is not statistically significant either. The same applies to the reaction time for incongruent trials for native monolinguals $(M=864.46, S D=222.12)$ and native bilinguals/multilinguals $(M=925.27, S D=204.02)$ conditions; $t(57)=-1.093, p=0.28$.

The Stroop effect values were also compared with the degrees of self-rated oral and written proficiency that the participants in the pilot study indicated in their questionnaires to find out whether there were any signs of a possible correlation that might be either confirmed or refuted by a study of a larger scale later on. The original hypothesis was that the participants who indicate a higher degree of native language proficiency would in all probability also be the ones who still use them on a regular basis and, therefore, might benefit from the sustained native language use in terms of improved inhibitory control and thus a lower Stroop effect. However, as Table 2 shows, hardly any correlation was identified in this respect. What should be considered, though, is that the sample group in this case is too small $(\mathrm{N}=30)$ for one to be able to come to any statistically significant conclusions.

Table 2: Correlation Between Stroop Effect and Proficiency in Bilinguals' (Multilinguals') Native Language 1.

\begin{tabular}{|c|c|c|c|c|c|c|}
\hline Number & $\begin{array}{c}\text { Mean } \\
\text { Stroop } \\
\text { Effect in ms }\end{array}$ & $S D$ & $\begin{array}{c}\text { Mean Oral Proficiency in } \\
\text { the Native Language 1 }\end{array}$ & SD & $\begin{array}{c}\text { Mean Written } \\
\text { Proficiency in the } \\
\text { Native Language 1 }\end{array}$ & SD \\
\hline 30 & 143.79 & 82.03 & 4.43 & 0.86 & 3.30 & 1.64 \\
\hline Correlation & & & -0.099 & & -0.043 & \\
\hline
\end{tabular}

\section{CONCLUSIONS}

The primary purpose of the pilot study was to evaluate the feasibility of a similar study of a larger scale and identify its possible obstacles or the issues that might arise during its execution. Its secondary goal was to investigate whether one can find any cognitive advantage in the form of enhanced executive functioning, namely inhibitory control, among those university students who have a command of more than one native language. The hypothesis that this might be the case with (bi-) multilingual participants was based on the findings of similar studies conducted among monolinguals and multilinguals (Bialystok \& Martin (2004), Bialystok (1999), Bialystok et al. (2008), Wang et al. (2016), etc.) indicating enhanced inhibitory control among the latter, which is believed to stem from their frequent exposure to more than one language and the necessity to suppress the language(s) not required by the immediate situation. Although none of the participants in the study can be considered a pure monolingual since all of them currently speak at least two languages, which are, in most cases, Swedish and English, the primary focus was on native monolingualism and (bi-) multilingualism and their possible effect on the inhibitory control at a later age. That is, the author was interested in whether the cognitive advantages identified by the earlier research in bilingual and multilingual 
children can still be traced in the individuals' adulthood when these are compared with non-native (bi-) multilinguals. The reason why special attention was paid to this question is that an answer to it might shed some light on whether exposing children to two or more L1s has some long-lasting effects at their later age or whether the same effects might be achieved merely via an L2 study in a language instructional setting, i.e. a school. Finally, the pilot study sought to investigate whether there could be any relationship between the degree of proficiency in the native languages in the (bi-) multilingual group and the Stroop effect. The original hypotheses were that those with more than one native language would manifest a better inhibitory control indicated by a lower value of the Stroop effect than the native monolinguals would and that the higher proficiency in the native languages among native (bi-) multilinguals, presumably indicative of their sustained use, would have a positive effect on their users' capacity to inhibit irrelevant stimuli.

As for the feasibility of a study of a larger scale, several issues were identified during the pilot phase. These were mostly related to the technical aspects of the study and its execution such recruiting volunteers willing to participate in it (not many students willing to take part without any kind of reward, so a reward-based system was established), making participants understand that it is the accuracy of the color identification process that matters, not only its speed, and ensuring that the questionnaires are designed the way that requires as little further explanation on the part of the researcher during the time they are being filled in as possible since these explanations appeared to disrupt the overall survey phase. It was also necessary to design a spreadsheet capable of calculating Stroop effect from the raw values saved on a server and providing information about the number of color identification errors the subjects made during the test since neither of these results were saved in the test file.

To measure the inhibitory control in the participants $(N=59)$ a computerized version of the Stroop test was used. The information about the participants' language history and the proficiency in their native languages was collected via questionnaires they were asked to fill in prior to taking the Stroop test. The comparison of the Stroop effect calculated from the participants' reaction times indicates a slightly higher (by app. $20 \mathrm{~ms}$ ), albeit statistically insignificant, value for the participants with more than one native language. The differences in the mean reaction times between the two groups in congruent and incongruent trials appear to be statistically insignificant as well. When it comes to the relationship between the Stroop effect and the proficiency in the native languages the native (bi-) multilingual participants indicated, no correlation has been found. However, what must be taken into account is the fact that the study group in this case was too small for one to be able to come to a conclusion backed up with statistically significant results.

Although this is a pilot study and its results should be viewed accordingly, one might hypothesize about why the results might tend to indicate no inhibitory control advantage for the native (bi-) multilinguals - something that has also been observed in other studies (e.g. Morton \& Harper (2007) or Kousaie \& Phillips (2012)). One of the reasons might be that the experiment was conducted in the language (English) that none of the participants uses as their native one and which all of them have learnt in a language instructional setting - an aspect that also represents the reason why English was chosen. That is, the selection of the language for the Stroop test is shown to affect the Stroop effect size by e.g. Heidlmayr et al (2014), which, in their study, was significantly higher for L1 than L2, or Sumiya \& Healy (2008), who point out that this variable can even be affected by phonological similarity between the language the subjects are proficient in and the one the Stroop test is performed in. In the pilot study described here, an attempt was made at utilizing a language that the monolinguals would not have an advantage in over the multilinguals as a result of the former using it as their mother tongue. Moreover, English represents the language that all the participants have studied in a language instructional setting and thus the color identification rule in the Stroop test had to be followed in the context of their previous knowledge that they have adopted at school. In this respect, the experiment made the participants apply a new cognitive concept requiring the inhibition of the semantic contents they have learnt at school before and prioritizing visual stimuli in the form of color instead. This way an attempt was made at inducing the situation activating those cognitive processes that resemble the ones put into operation in school environments when new concepts are learnt.

Another reason why no significant difference has been found within the study group might be that most participants are at the age at which, as Bialystok et al (2005) point out, the smallest differences in the Stroop effect are observed. This is probably due to young adults usually being at the peak of their cognitive potential at this stage of their life and thus the differences in their inhibitory control are not as marked as they appear to be in young children or the elderly. This also appears to be the case with the study conducted by Kousaie \& Phillips (2012), who found no Stroop effect differences in young and older adults. 
Some studies also mention the proficiency in the language in which the Stroop test is conducted as a factor affecting its results. Singh and Mishra (2013), for instance, tested high and low proficient bilinguals speaking Hindi and English and found out that high proficient bilinguals were faster in the Stroop task, showing that the L2 proficiency influences monitoring and resolution skills. Similarly, Roseli et al (2002) claim that while in balanced bilinguals the language used in the Stroop test did not matter, in the unbalanced subjects the best-spoken language showed better results. The fact that the proficiency of the language that the Stroop effect is measured in appears to affect its values represented another reason why English had been selected for the experiment as all the participants were within its relatively narrow proficiency range (B2 - C1 CEFR) - a fact allowing them to study some courses at the University in this language. However, no individual testing indicating the exact level of their proficiency in English that the Stroop effect could be related to had been carried out.

Some studies (Morton \& Harper (2007), Paap et al (2015), Mezzacappa (2004), Noble et al (2005) or Kousaie \& Phillips (2012)) also question the relationship between what is presented by others as a bilingual advantage in executive functioning and bilingualism per se ascribing any possible correlation between the two to demographic factors that tend to be distributed differently among monolinguals and (bi-) multinguals such as socio-economic or immigrant status, educational level, etc. In this respect, some authors stress the importance of matching groups participating in experiments for these factors carefully (e.g. Eneko et al (2016)).

Last but not least, English as well as other languages the subjects involved in the study have studied at school make all of them either bilinguals or multilinguals. This aspect might also "cognitively equalize" the native monolinguals and their native bi- or multilingual counterparts at a later age, thereby rendering the initial cognitive advantages stemming from native bi- or multilingualism impossible to observe later on. Hence, it is also the total number of languages that the subjects have a command of that might have an effect on their inhibitory control - an aspect that the author plans to focus on in the follow-up study of a larger sample size.

\section{REFERENCES}

[1] Antón, E., García, Y. F., Carreiras, M., Dunabeitia, J. A. Does bilingualism shape inhibitory control in the elderly?. Journal of Memory and Language, 90, 147-160, 2016.

[2] Badzakova-Trajkov, G., Waldie, G. K., Corballis, M., Kirk, I. The Stroop Effect in Bilinguals. The Abstracts of the $31^{\text {st }}$ Conference of the Australian Experimental Psychology Society. 104, 2004.

[3] Bialystok, E. Cognitive complexity and attentional control in the bilingual mind. Child Development, 70, 636-644, 1999.

[4] Bialystok, E., Craik, F. I. M., and Luk. Cognitive control and lexical access in younger and older bilinguals. Journal of Experimental Psychology: Learning, Memory, and Cognition 2008. Vol. 34, No. 4, 859-873, 2008.

[5] Bialystok, E. \& Martin, M. M. Attention and inhibition in bilingual children: evidence from the dimensional change card sort task. Developmental Science 7:3, 325-339, 2004.

[6] Bialystok, E., Martin M. \& Viswanathan, M. Bilingualism across the lifespan: The rise and fall of inhibitory control. International Journal of Bilingualism, 9(1), 103-119, 2005.

[7] Comalli, P. E., Jr., Wapner, S., \& Werner, H. Interference effects of Stroop color-word test in childhood, adulthood, and aging. The Journal of Genetic Psychology: Research and Theory on Human Development, 100, 47-53, 1962.

[8] Dagenbach, D. \& Carr, T. Inhibitory processes in attention, memory, and language. New York: Academic Press, 1994.

[9] Dempster, F. N. The rise and fall of the inhibitory mechanism: toward the unified theory of cognitive develoment and aging. Developmental Review, 12, 45-75, 1992.

[10] Eneko, A., Garcia, Y. F., Carreiras, M. \& Dunabeitia, J. A. Does bilingualism shape inhibitory control in the elderly?. Journal of Memory and Language, 90, 147-160, 2016.

[11] Eriksen, B. A. \& Eriksen, C. W. Effects of noise upon the identification of a target letter in a nonsearch task. Perception and Psychophysics, No. 1, 143-149, 1974. 
[12] Grosjean, F. (1982). Life with two languages: an introduction to bilingualism. Cambridge, Mass.: Harvard University Press. 370 pages.

[13] Heidlmayr, K., Moutier, S., Hemforth, B., Courtin, C., Tanzmeister, R., Isel, F. Bilingualism: Language and Cognition, Vol.17(3), pp.630-645, 2014.

[14] Hübner, R., Mishra, S. Evidence for strategic suppression of irrelevant activation in the Simon task. Acta Psychologica, 144, 166-172, 2013.

[15] Ivnik, R.J., Malec, J.V., Smith, G.E., Tangalos, E.G., \& Petersen, R.C. Neuropsychological tests' norms above age 55: COWAT, BNT, MAE, Token, WRAT-R Reading, AMNART, STROOP, TMT, and JLO. Clinical Neuropsychologist, 10, 262-278. in Rosseli, M., Ardila, A., Santisi, M.N., Arecco, M.D.R., Salvatierra, J., Conde, A. \& Lenis, B. (2002). Stroop effect in Spanish-English bilinguals. Journal of the Interantional Neuropsychological Society, 8, 819-827, 1996.

[16] Kline, L. W., An experimental study of associative inhibition. Journal of Experimental Psychology 4, 270-299. In: Stroop, R. Studies of Interference in Serial Verbal Reactions. Journal of Experimental Psychology, 18, 643-662, 1935.

[17] Kousaie, S., \& Phillips, N. A. Ageing and bilingualism: Absence of a "bilingual advantage" in Stroop interference in a nonimmigrant sample. The Quarterly Journal of Experimental Psychology, 65, 356-369, 2012.

[18] Mezzacappa, E. Alerting, orienting, and executive attention: Developmental properties and sociodemographic correlates in an epidemiological sample of young, urban children. Child Development, (75)5, 1373-1386, 2004.

[19] Miyake, A. \& Friedman, N. P. The nature and organization of individual differences in executive functions: four general conclusions. Current Directions in Psychological Science, 21(1) 8-14, 2012.

[20] Morton, J. B., Harper. S. N. What did Simon say? Revisiting the bilingual advantage. Developmental Science, 10:6, 719-726, 2007.

[21] Noble, K. G., Norman, M. F., \& Farah, M. J. Neurocognitive correlates of socioeconomic status in kindergarten children. Developmental Science, 8(1), 74-87, 2005.

[22] Paap, K. R., Johnson, H. A., \& Savi, O. Bilingual advantages in executive functioning either do not exist or are restricted to very specific and undetermined circumstances. Cortex, 69, 265278, 2015.

[23] Proctor, R. W. Playing the Simon game: Use of the Simon task for investigating human information processing. Acta Psychologica, 136, 182-188, 2011.

[24] Rosselli, M., Ardila, A., Santisi, M.N., Arecco, M.D.R., Salvatierra, J., Conde, A. \& Lenis, B. Stroop effect in Spanish-English bilinguals. Journal of the International Neuropsychological Society, 8, 819-827, 2002.

[25] Simon, J. R. Reactions toward the source of stimulation. Journal of Experimental Psychology, 81, 174-176, 1969.

[26] Singh, N. \& Mishra, R. K. Second language proficiency modulates conflict-monitoring in an oculomotor Stroop task: Evidence from Hindi-English bilinguals. Frontiers in Psychology, 4, 322, 2013.

[27] Stroop, R. Studies of Interference in Serial Verbal Reactions. Journal of Experimental Psychology, 18, 643-662, 1935.

[28] Sumiya, H. \& Healy. A. The Stroop effect in English-Japanese bilinguals: The effect of phonological similarity. Experimental Psychology. Vol. 55, Iss. 2, 93-101, 2008.

[29] Wang, R., Fan, X., Liu, C., Cai, Z. G. Cognitive control and word recognition speed influence the Stroop effect in bilinguals. International Journal of Psychology. Vol. 51, No. 2, 93-101, 2016.

[30] Yang, S. \& Lust, B. (n.d.). Testing effects of bilingualism on executive attention: comparison of cognitive performance on two non-verbal tests. Retrieved from http://www.bu.edu/bucld/files/2011/05/29-YangBUCLD2004.pdf (2018) 
[31] Yow, W. Q., Li, X. Balanced bilingualism and early age of second language acquisition as the underlying mechanisms of a bilingual executive control advantage: why variations in bilingual experiences matter. Frontiers in Psychology: Language Sciences. Vol. 6. Article 164, 2015. 